\title{
Left Bundle Branch Area Pacing as an alternative to His Bundle pacing for Cardiac Resynchronization Therapy: a case report.
}

Jean-Yves Wielandts ${ }^{1}$, Alexandre Almorad ${ }^{1}$, Gabriela Hilfiker ${ }^{2}$, Anais Gauthey ${ }^{3}$, Sebastien Knecht $^{4}$, Mattias Duytschaever ${ }^{4}$, Yves Vandekerckhove ${ }^{5}$, Rene Tavernier ${ }^{6}$, and Jean-Benoit le Polain de Waroux ${ }^{7}$

${ }^{1} \mathrm{AZ}$ Sint-Jan AV

${ }^{2}$ AZ Sint-Jan Brugge-Oostende AV

${ }^{3}$ Cliniques universitaires Saint-Luc

${ }^{4}$ Sint-Jan Hospital

${ }^{5}$ General Hospital Saint-Jan

$\left.{ }^{6} 17\right)$ Az Sint-Jan Brugge,

${ }^{7}$ Clinique Universitaire Saint-Luc (UCL)

July 16, 2020

\begin{abstract}
Biventricular pacing (BVP) has been demonstrated to improve functional outcomes and mortality of patients with symptomatic heart failure, reduced LVEF and wide QRS. Unfortunately, difficult coronary sinus anatomy can limit left ventricular lead placement. In such clinical situation, His Bundle Pacing (HBP) and Left Bundle Branch Area Pacing (LBBAP) have recently appeared as attractive alternatives to BVP. We describe the case of a patient with an indication for Cardiac Resynchronization Therapy (CRT) and AV node ablation, where left ventricular lead implantation and corrective HBP failed. LBBAP allowed for electrical and echocardiographic resynchronization with significant functional improvement.
\end{abstract}

\section{Hosted file}

LBBAP_CR_final.pdf available at https://authorea.com/users/343595/articles/470228-

left-bundle-branch-area-pacing-as-an-alternative-to-his-bundle-pacing-for-cardiac-

resynchronization-therapy-a-case-report 